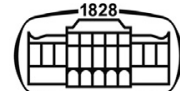

AKADÉMIAI KIADÓ

Acta Chromatographica

33 (2021) 1, 57-63

DOI:

$10.1556 / 1326.2020 .00753$

(c) 2020 The Authors

ORIGINAL RESEARCH PAPER

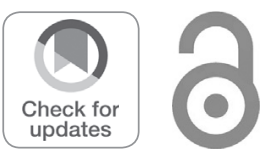

\title{
Development and validation of GC/MS method for simultaneous determination of 16 polycyclic aromatic hydrocarbons (PAHs) in pork meat matrix
}

\author{
IVAN GIVECHEV ${ }^{1,2}$, DIMITAR TANEV ${ }^{2}$ and \\ DANCHO DANALEV $^{1 *}$ ๑
}

\author{
${ }^{1}$ Biotechnology Department, University of Chemical Technology and Metallurgy, 8 blvd. Kliment \\ Ohridski, Sofia, Bulgaria \\ ${ }^{2}$ Testing center Global Test Ltd, 31 Krushovski vrah Street, Sofia, Bulgaria
}

Received: November 30, 2019 • Accepted: December 17, 2019

Published online: April 16, 2020

\begin{abstract}
The major processes for introducing polycyclic aromatic hydrocarbons (PAHs) in food are smoking and grilling of different products. But in addition, PAHs can permeate in the food chain due to their high lipophilicity and ability to be accumulated in specific tissue, through contaminated animal feed. Further, when some parts of these animals are marketed as food, the accumulated PAHs can go to the human organism. Some of them are classified as highly toxic, carcinogenic and mutagenic for animal and human organisms so they are under consideration of International and European legislation. This work reports development and validation of simple and fast GC/MS method for 16 PAHs determination. Comparison of two methods for sample preparation in pork meat matrix standard extraction/saponification procedure and modified QuEChERS method is also done. In addition, this paper report the calibration step of instrument and a recovery study for 16 PAHs in model pork meat, using modified QuEChERS procedure for sample pretreatment. The calibration step with accessible and suitable for use in real laboratory conditions internal standard (chrysene $D_{12}$ ) is done in the range 10-100 ppb using toluene as solvent. The obtained results show very good linearity $\left(\mathrm{R}^{2}=0.99\right.$ to 1.00$)$. For the recovery study six model samples were spiked with 16 PAHs and they all are subjected to QuEChERS procedure. The recovery is calculated and the obtained data $(71-120 \%)$ is in a good correlation with requirements of international legislation. Finally, LOD values for all 16 investigated compounds of modified GC/MS method and for the instrument were determined.
\end{abstract}

\section{KEYWORDS}

polycyclic aromatic hydrocarbons (PAHs), GC/MS analysis, QuEChERS procedure for sample preparation

\section{INTRODUCTION}

The group of polycyclic aromatic hydrocarbons (PAHs) is largely distributed in the nature [1]. They contain two or more fused aromatic rings. They are formed as a result of many natural and anthropogenic processes. The two main sources are pyrogens (incomplete combustion of coal, oil, gas, wood, waste or other organic substances) and petrogenic pathways [2-4]. The major processes for introducing PAHs in food are smoking and grilling of different products. A lot of other sources of contamination especially of plants further used as a row materials for production of different good as well as for direct food of animals or humans are described in the scientific literature among which contaminated soil [5-7], particles from air [8, 9], contamination of different oils during process of their production [10] and many other [1114]. PAHs can be also largely distributed in a seafood directly used for cooking [15-17]. Finally, PAHs can permeate in the food chain due to their high lipophilicity and ability to be 
accumulated in specific tissue, through contaminated animal feed. Further, when some parts of these animals are marketed as food, the accumulated PAHs can go to the human organism [18]. Moreover, part of this substances, those with 46 fused rings are described and classified as carcinogenic and mutagenic both for human and animal organisms and they are of a special apprehension [19-21].

Due to the high toxicity of some of PAHs and harmful effect on human health, they are under consideration of International and European legislation [22, 23]. In present days there are methods for determination of PAHs in one or several matrices using different kind of instrumental technics. The most common are HPLC combined with fluorescent detection and gas chromatography with mass spectrometric detection [24-29]. There is scarce data in the scientific literature for methods for determining of all 16 PAHs in specific matrices and often they are related to the specific apparatus or method for sample preparation [30-32].

Process of sample preparation is very important part of every analytical procedure. This process is different depending on the fat content in the matrix. Related to the PAHs determination often it is a long complicated procedure needed by specific apparatus or reagents [33-35].

In our previous work we tried to find an appropriate internal standard to replace used in EN 16619:2015 method ${ }^{13} \mathrm{C}$ labeled internal standard benzo[a]pyrene ${ }^{13} \mathrm{C}_{4}$ and to make some modifications in the method for determination of only benzo[a]pyrene in two matrices wheat flour and smoked pork leg. The main purpose of this investigation was to adapt an internal standard that would make the method applicable in real laboratory conditions for analysis, since one of the components of the final cost of the analysis is the price of the standards used. Used in the document EN 16619:2015 benzo [a]pyrene ${ }^{13} \mathrm{C}_{4}$ as an internal standard is relatively expensive, which of course will also affect the final cost of the analyzes. Finally we succeed to modified methods conditions in order to use cheaper and more available Chrysene $\mathrm{D}_{12}$ as an internal standard and to cover the requirements of European legislation according to recovery rates for benzo[a]pyrene [36]. Further, we continued our work on the modification of procedure and herein we report the development and validation of GC/MS method suitable for determination of all 16 PAHs under International and European legislation, in smoked pork meat matrix using Chrysene $\mathrm{D}_{12}$ as an internal standard. In addition, we compare two methods for sample preparation - a standard one (Soxhlet extraction, saponification and clean up) and modified QuEChERS (Quick, Easy, Cheap, Effective, Rugged and Safe) method for smoked pork meat samples. The GC conditions were also been developed in order to improve the sensitivity and selectivity of the chromatographic system.

\section{MATERIALS AND METHODS}

Chrysene $\mathrm{D}_{12}$ purchased by Supelco is prepared with concentrationo of $658 \mathrm{ng} / \mathrm{g}$ in toluene.

CRM PAH 16 Compounds mix $500 \mathrm{ug} / \mathrm{mL}$ for calibration and determination is purchased by Reagecon
Diagnostics Ltd (Shannon, Ireland). $\mathrm{KOH}$ is purchased by Sigma-Aldrich (Deisenhofen, Germany).

QuEChERS extract pouch Bond Elut 5982-6650 is purchased by Agilent Technologies.

SPE test tube Bond Elut 5982-5056 is purchased by Agilent Technologies (Sofia, Bulgaria). SPE test tube $0.5 \mathrm{~g}$ silica gel (Sigma Aldrich, Deisenhofen, Germany) $+0.5 \mathrm{~g}$ sodium sulfate (Sigma Aldrich, Deisenhofen, Germany) is prepared in laboratory.

Chilled vacuum smoked pork meat is used for this investigation. All used solvents were analytical grade and they are used without any additional treatment.

\section{Standard solution preparation}

All calibration solutions (concentration range in final calibration solutions) in the working range $10-100 \mathrm{ng} / \mathrm{g}$ are prepared gravimetrically in toluene. For all 16 aimed PAHs and chrysene $\mathrm{D}_{12}$ initial stock solutions with four concentrations 21.7; 41.6; 101.2 and 201.2 [ng/g] for PAHs and around $150[\mathrm{ng} / \mathrm{g}]$ for Chrysene $\mathrm{D}_{12}$ are used. Starting form stock solutions, calibration solutions with four concentration 10.8; 20.6; 51.2; 101.5 [ng/g] for PAHs and 70 [ng/g] for Chrysene $\mathrm{D}_{12}$ are prepared by mixing with internal standard solution.

\section{Chromatographic conditions}

GC conditions. GC column SLB-5 MS (Supelco, Merck KGaA, Darmstadt, Germany) 30 m $0.32 \mathrm{~mm}$ i. d.' 0.25 $\mu \mathrm{m}$ film thickness. Column oven temp.: $70{ }^{\circ} \mathrm{C}$; Injection temp.: $300{ }^{\circ} \mathrm{C}$; Injection mode: Splitless; Sampling time: $0.50 \mathrm{~min}$; Flow control mode: Linear velocity; Inlet pressure: $52.3 \mathrm{kPa}$; Total flow: $78 \mathrm{~mL} / \mathrm{min}$; Column flow: 3 $\mathrm{mL} / \mathrm{min}$; Purge flow: $15 \mathrm{~mL} / \mathrm{min}$; High pressure injection: ON (150 kPa for $0.50 \mathrm{~min}$ ); Oven temperature program: $70{ }^{\circ} \mathrm{C}$ (hold $\left.2 \mathrm{~min}\right)$; ramp $1\left(8-300{ }^{\circ} \mathrm{C}\right)$; ramp $2\left(20-340{ }^{\circ} \mathrm{C}\right.$, hold $10 \mathrm{~min})$.

MS conditions. Ion source temp.: $220^{\circ} \mathrm{C}$; Interface temp.: $300{ }^{\circ} \mathrm{C}$; Solvent cut time: $3 \mathrm{~min}$; MS mode: SIM; Monitored ions are presented in Table 1.

\section{Standard extraction and clean up procedure for sample preparation}

Step 1. Soxhlet extraction

Five grams of smoked pork meat is mixed with $5 \mathrm{~g}$ of sodium polyacrilate and $5 \mathrm{~g}$ sand. To the obtained mixture $200 \mu \mathrm{L}$ internal standard chrysene $\mathrm{D}_{12}$ are added and sample is homogenized in the mortar. Further, the obtained mixture is subjected to the Soxhlet extraction in $100 \mathrm{~mL}$ of hexane for $7 \mathrm{~h}$. Further, the solvent is evaporated under vacuum.

\section{Step 2. Saponification}

Four milliliter $60 \% \mathrm{KOH}$ in water and $8 \mathrm{~mL}$ of ethanol are added to the raw extract from step 1 . The obtained solution is shacked $10 \mathrm{~min}$ on vortex. The mixture is put in 50 $\mathrm{mL}$ tube and it is extracted with $3 \times 20 \mathrm{~mL}$ hexane. The organic layers are collected and concentrated under vacuum. 
Table 1. Retention time, target, and referenced monitored ions for aim compounds

\begin{tabular}{|c|c|c|c|c|c|}
\hline No & Name & $t_{R} \min$ & $\begin{array}{c}\text { Target ion } \\
\mathrm{m} / \mathrm{z}\end{array}$ & $\begin{array}{c}\text { Ref. ion } 1 \\
\mathrm{~m} / \mathrm{z}\end{array}$ & $\begin{array}{c}\text { Ref ion } 2 \\
\mathrm{~m} / \mathrm{z}\end{array}$ \\
\hline 1 & Naphthalene & 5.90 & 128 & 127 & 129 \\
\hline 2 & Acenaphthylene & 10.23 & 152 & 151 & 76 \\
\hline 3 & Acenaphtene & 10.75 & 153 & 154 & 152 \\
\hline 4 & Fluorene & 12.25 & 166 & 165 & 82 \\
\hline 5 & Phenanthrene & 14.97 & 178 & 176 & 89 \\
\hline 6 & Anthracene & 15.12 & 178 & 176 & 89 \\
\hline 7 & Fluoranthene & 18.42 & 202 & 101 & 200 \\
\hline 8 & Pyrene & 19.01 & 202 & 101 & 200 \\
\hline 9 & $\begin{array}{l}\text { Benz }[\mathrm{a}] \\
\quad \text { anthracene }\end{array}$ & 22.57 & 228 & 226 & 114 \\
\hline 10 & Chrysene & 22.66 & 228 & 226 & 229 \\
\hline 11 & $\begin{array}{l}\text { Benzo[b] } \\
\text { fluoranthene }\end{array}$ & 25.49 & 252 & 126 & 250 \\
\hline 12 & $\begin{array}{l}\text { Benzo }[\mathrm{k}] \\
\quad \text { fluoranthene }\end{array}$ & 25.56 & 252 & 126 & 250 \\
\hline 13 & Benzo[a]pyrene & 26.26 & 252 & 126 & 250 \\
\hline 14 & $\begin{array}{l}\text { Indeno }[1,2,3-c d] \\
\text { pyrene }\end{array}$ & 28.82 & 276 & 138 & 277 \\
\hline 15 & $\begin{array}{l}\text { Dibenzo[a,h] } \\
\text { anthracene }\end{array}$ & 28.93 & 278 & 139 & 279 \\
\hline 16 & $\begin{array}{l}\text { Benzo[g,h,i] } \\
\text { perylene }\end{array}$ & 29.33 & 276 & 138 & 137 \\
\hline 17 & Chrysene $\mathrm{D}_{12}$ & 22.56 & 240 & 238 & 236 \\
\hline
\end{tabular}

Step 3. Solid phase extraction (SPE)

The obtained raw concentrate from step 2 is mixed with $200 \mu \mathrm{L}$ of toluene and the volume of sample is reduced to $1 \mathrm{~mL}$ under nitrogen atmosphere. The obtained residue is put on SPE column containing $0.5 \mathrm{~g}$ silica gel and $0.5 \mathrm{~g}$ sodium sulfate. The aim compounds are eluted gravitationally with $10 \mathrm{~mL}$ of hexane. The obtained sample is concentrated under vacuum to $0.5 \mathrm{~mL}$ final volume and injected to GC/MS system.

\section{QuEChERS procedure for sample preparation}

Five grams homogenized sample is placed in $50 \mathrm{~mL}$ polypropylene tube. Internal standard chrysene $\mathrm{D}_{12}$ solution 0.9 $\mathrm{mL}$ is added. Further, $0.084 \mathrm{~g}$ spiking standard solution of all 16 PAHs with concentration 5,000 ng/g is added. The tube is shake vigorously for $1 \mathrm{~min}$ on a vortex. After $8 \mathrm{~mL}$
Table 2. The characteristics of linearity for studied substances in investigated range 10.83-101.53 [ng/g]

\begin{tabular}{lcc}
\hline Name & Regression equation & $R^{2}$ \\
\hline Naphthalene & $2.0054 \mathrm{x}+0.1162$ & 0.99 \\
Acenaphthylene & $1.9917 \mathrm{x}+0.0253$ & 0.99 \\
Acenaphthene & $1.2985 \mathrm{x}+0.0110$ & 0.99 \\
Fluorene & $1.1542 \mathrm{x}-0.0019$ & 0.99 \\
Phenanthrene & $1.0961 \mathrm{x}-0.0430$ & 0.99 \\
Anthracene & $1.4800 \mathrm{x}+0.0295$ & 0.99 \\
Fluoranthene & $1.1625 \mathrm{x}+0.0054$ & 1.00 \\
Pyrene & $1.2531 \mathrm{x}+0.0122$ & 0.99 \\
Benz[a]anthracene & $0.4639 \mathrm{x}+0.0563$ & 0.99 \\
Chrysene & $1.5014 \mathrm{x}+0.0300$ & 1.00 \\
Benzo[b]fluoranthene & $0.7430 \mathrm{x}-0.0349$ & 0.99 \\
Benzo[k]fluoranthene & $1.6465 \mathrm{x}+0.0382$ & 0.99 \\
Benzo[a]pyrene & $0.7632 \mathrm{x}+0.0089$ & 0.99 \\
Indeno[1,2,3-cd]pyrene & $0.9999 \mathrm{x}+0.0030$ & 0.99 \\
Dibenz[a,h]anthracene & $0.9160 \mathrm{x}-0.0085$ & 0.99 \\
Benzo[ghi]perylene & $1.1544 \mathrm{x}+0.0066$ & 0.99 \\
\hline
\end{tabular}

acetonitrile is added and the tube is again shacked vigorously for $1 \mathrm{~min}$ on a vortex. One QuEChERS extract pouch (Agilent 5982-6650) is added, sample is shacked $1 \mathrm{~min}$ and centrifuge at 5,000 rpm for $5 \mathrm{~min}$. Six milliliter from the obtained extract is transferred to $15 \mathrm{~mL}$ dispersive SPE test tube (Agilent 5982-5056), shacked for $1 \mathrm{~min}$ and centrifuged at $5,000 \mathrm{rpm}$ for $5 \mathrm{~min}$. $1 \mu \mathrm{L}$ of obtained extract is injected in chromatographic system.

\section{RESULTS AND DISCUSSION}

Herein, we reported the development of GC conditions and calibrating step of GC/MS instrument as well as a recovery study for 16 PAHs under control of international legislation in smoked pork meat sample using both standard (extraction and clean up) method and modified QuEChERS procedure for sample pretreatment.

Taking into account our preliminary investigations on the topic described in Givechev et al. 2018, herein an internal standard crysene $\mathrm{D}_{12}$ is used [36]. We also modified the chromatographic conditions according to those used in Givechev et al. 2018 in order to improve sensitivity and

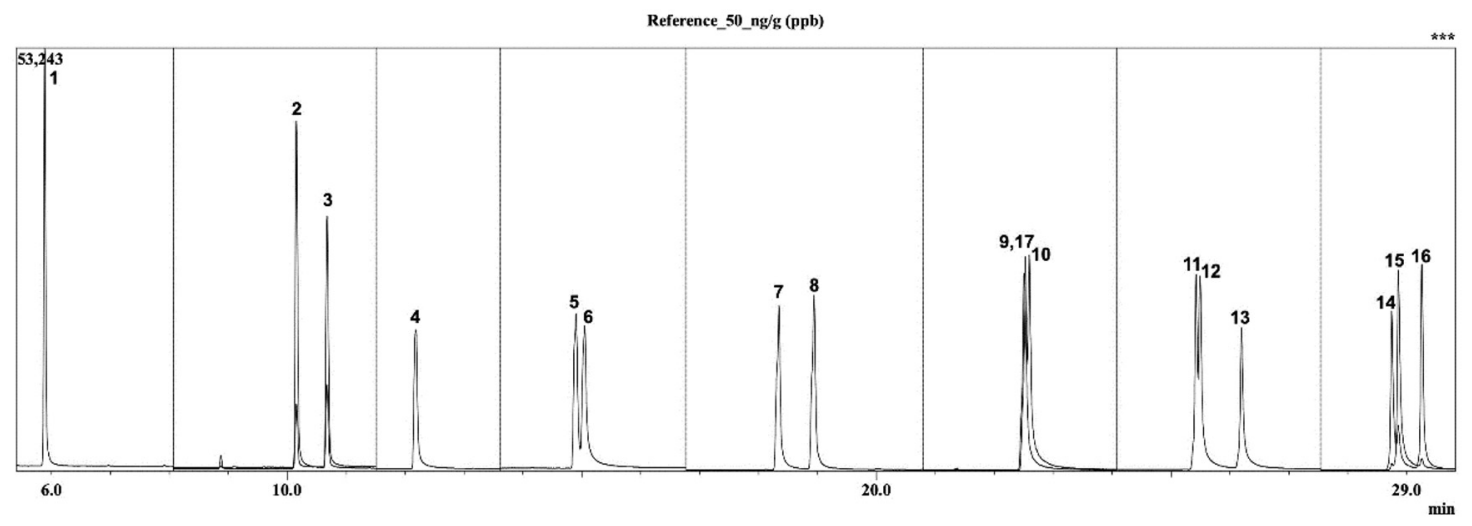

Figure 1. Identification chromatogram in SIM mode of standard solution of all 16 aimed PAHs with concentration $50 \mathrm{ppb}$ 
A

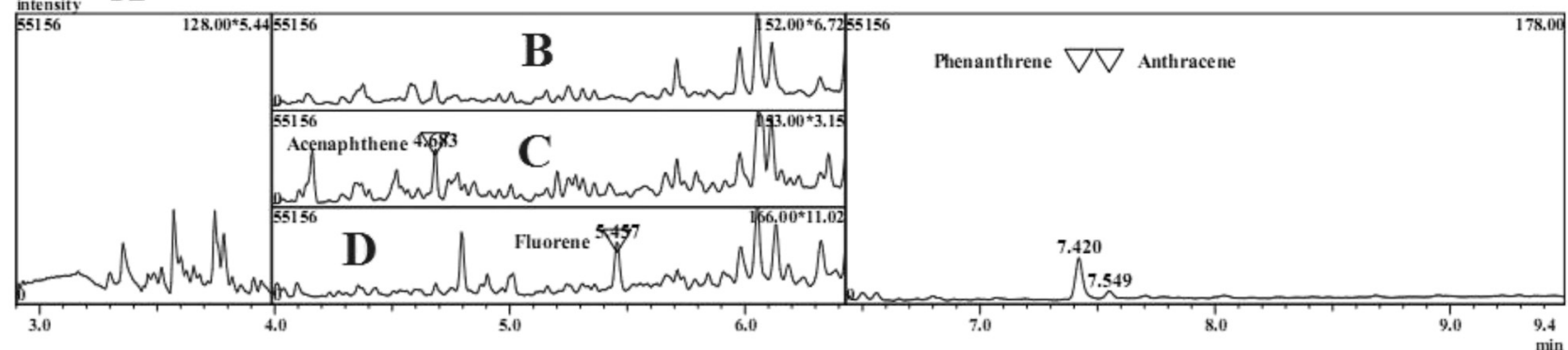

GC/MS Chromatogram Spiked PAHs
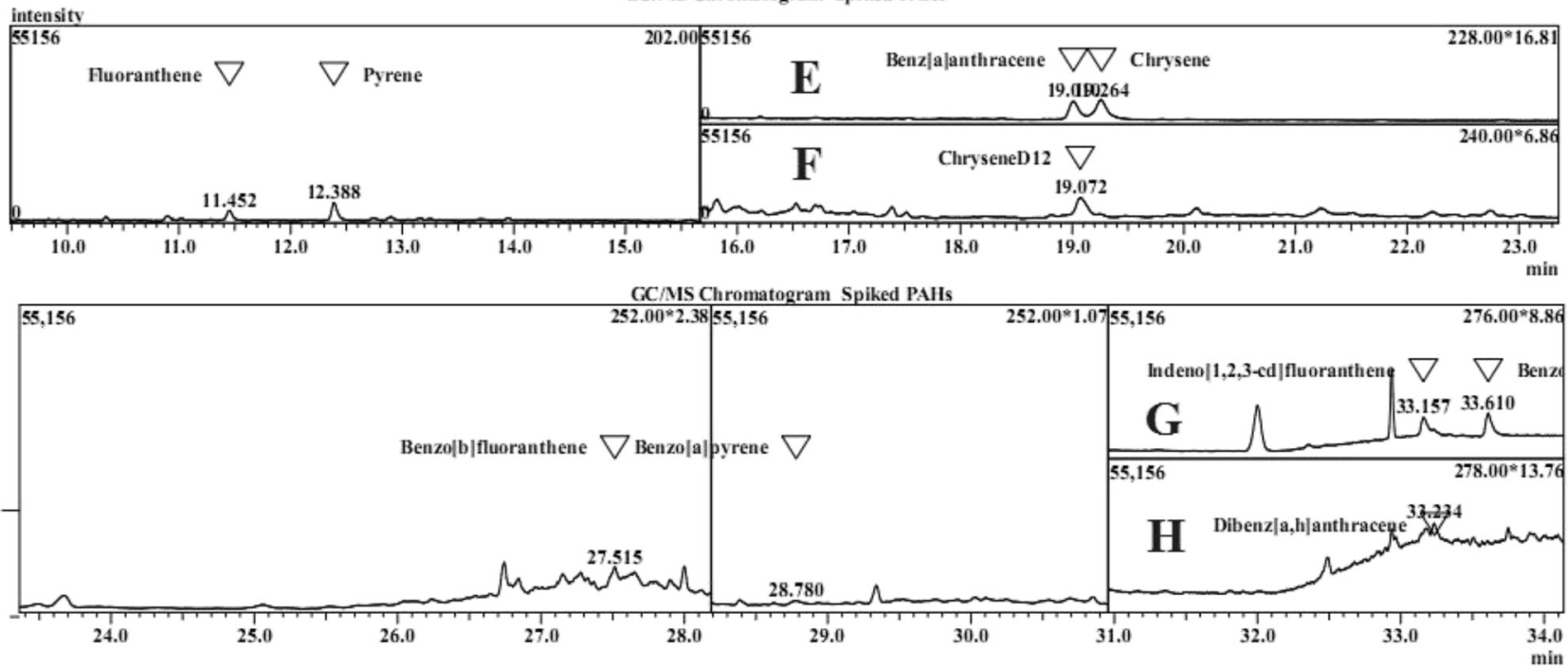

Figure 2. A. Chromatogram of aimed compounds after Soxhlet extraction and saponification as sample preparation procedure; $\mathbf{B}, \mathbf{C}$ and $\mathbf{D}$ are zoomed parts of chromatogram between 4.0 and $6.4 \mathrm{~min}$ in order to determine compounds with closed $t_{R}$ in the interval; $\mathbf{E}$ and $\mathbf{F}$ are zoomed parts of chromatogram between 15.7 and $23.3 \mathrm{~min}$ in order to determine compounds with closed $t_{R}$ in the interval; $\mathbf{G}$ and $\mathbf{H}$ are zoomed parts of chromatogram between 31.0 and $40.0 \mathrm{~min}$ in order to determine compounds with closed $t_{R}$ in the interval

selectivity of the chromatographic system [36]. The obtained chromatogram in SIM mode of standard solution of all 16 aimed PAHs with concentration $50[\mathrm{ng} / \mathrm{g}]$ at new optimized chromatographic conditions described above in materials and methods section is presented on Fig. 1 and their identification retention times in Table 1.

For the calibration step a set of calibration standards in concentration range from $10 \mathrm{ng} / \mathrm{g}$ to $100 \mathrm{ng} / \mathrm{g}$ were prepared gravimetrically. Then an internal standard procedure using chrysene $\mathrm{D}_{12}$ for calibration is realized and calibration curves were created using 4 points with concentrations 10 , 20,50 , and $100 \mathrm{ng} / \mathrm{g}$. The results of calibration step show very good linearity $\mathrm{R}^{2}$ from 0.99 to 1.00 for all 16 studied PAHs in the working range $10-100 \mathrm{ng} / \mathrm{g}$ that fit with the legislation (Table 2).

The process of sample pretreatment play key role in the successful separation and analysis of aim component. In addition the approach used for sample preparation is different according to the fat content of sample and fat content samples needs to pass more complicate procedure in order to remove fat content. Next step of our work was to investigate different procedures for sample pretreatment. The matrix of smoked pork was especially selected as a high fat content matrix. Three samples of smoked pork meat were subjected to a standard extraction and clean up procedure as it is described in the material and methods section. The whole procedure was realized in three stages and it took around $16 \mathrm{~h}$ (separated in 2 days). The obtained samples are further injected to the GC/MS system, using chromatographic conditions from our preliminary investigations and resulting chromatogram is presented on Fig. 2 [36].

It can be clearly seen from the obtained chromatogram (Fig. 2) that there are undesired compounds from the matrix which pass through the sample preparation procedure together with aimed compounds. Moreover, some of them interfere determination of several of target compounds (naphthalene, acenaphthylene, benzo[k]fluoranthene) which are completely covered by matrix component or reduce the recovery rates. On the other hand the used GC conditions have shown low sensitivity.

In order to optimize the process of sample preparation according to the time of process and purity of obtained for analysis samples as well as to realize our aim, to determine simultaneously all 16 aimed PAHs, a modified QuEChERS method for sample preparation and modified chromatographic 

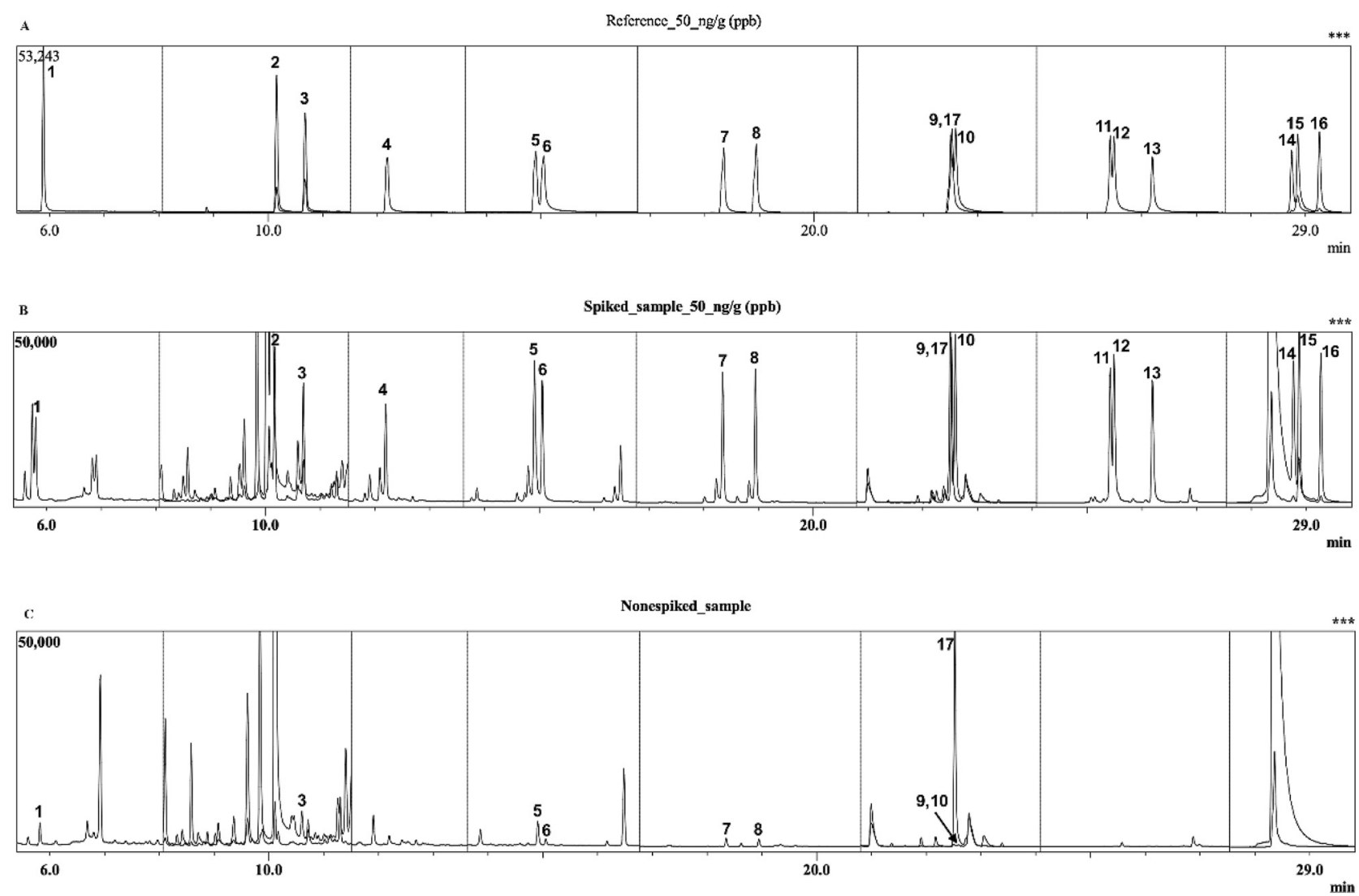

Figure 3. Chromatograms of aimed compounds after QuEChERS procedure for sample preparation procedure: A. Reference compounds at $50 \mathrm{ppb}$ concentration, B. Spiked sample with $50 \mathrm{ppb}$ concentration of aimed compounds, C. Matrix without spiking

conditions described in material and methods section was used. Some other authors also report for QuEChERS procedures for sample preparation. According to Surma et al. in 2014 QuEChERS method for application for PAHs determination in food of animal origin has not been reported as yet [37]. Authors experimented different stationary and mobile phases in order to achieve the best results according to linearity, selectivity, recovery, repeatability, the limit of detection (LOD) and limit of quantification (LOQ). Their experiments reveal that ethylacetate as solvent as well as primary-secondary amines (PSA) and C18 as sorbents are the best choice for extraction of studied samples of animal origin. One year later Khorshid et al. apply QuEChERS method for determination of PAHs in fish. The used QuEChERS method is followed by additional cleanup procedure of solid phase extraction [15]. In 2018 Al-Thaiban et al. reported for development of QuEChERS method for determination of PAHs in smoked meat products for Quatar [38]. The described method include several steps taking around $1 \mathrm{~h}$ of sample preparation, several solvents are used as well as centrifugation procedure and heating for concentration of sample. In our case the procedure takes only about $15 \mathrm{~min}$ and usual laboratory equipment is used. Moreover only acetonitrile is used like a solvent. The key modification in the chromatographic conditions was changing in the column dimensions and injection conditions. Dimensions of the new column provided more sample loading and both with injection corrections more sensitivity of the instrument. The obtained chromatogram after QuEChERS method purification is presented on Fig. 3.

Table 3. Comparison between two sample preparation procedures

\begin{tabular}{|c|c|}
\hline Standard procedure & Modified QuEChERS method \\
\hline $\begin{array}{l}3 \text { steps procedure } \\
\text { many steps (large possibility } \\
\text { of losses of aimed PAHs) } \\
\text { time consuming procedure } \\
\text { very unclear matrix, because } \\
\text { of using of very strong } \\
\text { nonpolar solvents (hexane, } \\
\text { toluene) able to extract } \\
\text { many undesired compounds } \\
\text { of matrix }\end{array}$ & $\begin{array}{l}1 \text { step procedure } \\
\text { small possibility of losses } \\
\text { of PAHs } \\
\text { time-saving procedure } \\
\text { there are no extracted } \\
\text { interfered compounds }\end{array}$ \\
\hline $\begin{array}{l}\text { Coextraction of large } \\
\text { amounts of fats }\end{array}$ & $\begin{array}{l}\text { Coextraction of insignificant } \\
\text { amounts of fats }\end{array}$ \\
\hline $\begin{array}{l}\text { Need for saponification of } \\
\text { fats in order to be removed } \\
\text { from the aim extract }\end{array}$ & $\begin{array}{l}\text { No needs of saponification } \\
\text { step }\end{array}$ \\
\hline $\begin{array}{l}\text { High costs of time and } \\
\text { reagents }\end{array}$ & $\begin{array}{l}\text { Significantly lower costs of } \\
\text { time and reagents }\end{array}$ \\
\hline Low recovery & $\begin{array}{l}\text { High recovery fitting in the } \\
\text { legislation }\end{array}$ \\
\hline $\begin{array}{l}\text { Low sensitivity because of } \\
\text { presence of high levels of } \\
\text { matrix impurities }\end{array}$ & $\begin{array}{l}\text { High sensitivity because of luck } \\
\text { of interfered compounds }\end{array}$ \\
\hline
\end{tabular}


Table 4. Recovery data for all $16 \mathrm{PAHs}$

\begin{tabular}{llccclrr}
\hline No & Name & Recovery $\%$ & RSD $\%[n=6]$ & No & Name & Recovery $\%$ & RSD\% $[n=6]$ \\
\hline 1 & naphthalene & 81 & 7.6 & 9 & benzo[a]anthracene & 100 & 4.0 \\
2 & acenaphthylene & 89 & 5.6 & 10 & chrysene & 91 & 1.9 \\
3 & acenaphthene & 92 & 4.6 & 11 & benzo[b]fluoranthene & 90 & 4.4 \\
4 & fluorene & 97 & 5.3 & 12 & benzo[k]fluoranthene & 104 & 120 \\
5 & phenantrene & 89 & 2.8 & 13 & benzo[a]pyrene & 7.3 & 4.3 \\
6 & anthracene & 86 & 4.3 & 14 & indeno[1,2,3,-cd]pyrene & 71 & 5.6 \\
7 & fluoranthene & 91 & 2.9 & 15 & dibenzo[a,h]anthracene & 120 & 5.9 \\
8 & pyrene & 91 & 1.7 & 16 & benzo[g,h,j]perylene & 104 & 4.9 \\
\hline
\end{tabular}

Table 5. LOD values of instrument (LODi) and of method (LODm) for all 16 investigated PAHs

\begin{tabular}{llcc}
\hline No & Substance & LODi, ng/g & $\begin{array}{c}\text { LODm, } \\
\text { ug/kg }\end{array}$ \\
\hline 1 & Naphthalene & 0.45 & 0.90 \\
2 & Acenaphthylene & 0.22 & 0.45 \\
3 & Acenaphthene & 0.29 & 0.58 \\
4 & Fluorene & 0.25 & 0.50 \\
5 & Phenanthrene & 0.14 & 0.29 \\
6 & Anthracene & 0.17 & 0.35 \\
7 & Fluoranhene & 0.13 & 0.27 \\
8 & Pyrene & 0.18 & 0.35 \\
9 & Benz[a]anthracene & 1.92 & 3.85 \\
10 & Chrysene & 1.12 & 2.24 \\
11 & Benzo[b]Fluoranthene & 2.29 & 4.57 \\
12 & Benzo[k]Fluoranthene & 2.35 & 4.69 \\
13 & Benzo[a]pyrene & 1.66 & 3.33 \\
14 & Indeno[1,2,3-cd] & 2.87 & 5.74 \\
& pyrene & & \\
15 & Dibenz[a,h]anthracene & 2.52 & 5.05 \\
16 & Benzo[ghi]perylene & 2.80 & 5.60 \\
\hline
\end{tabular}

The corresponding LOQ values can be calculated using the relationship between LOQ and LOD values, $L O Q=3{ }^{\star} L O D$.

As it can be clearly seen from the chromatograms on Fig. 3 all 16 investigated PAHs are well separated and detected.

Some comparison and short conclusions for two used methods for sample preparation are summarized in Table 3.

Further, the recovery study was realized on six replicates of $5 \mathrm{~g}$ of smoked pork meat using modified QuEChERS method for sample preparation. All 6 samples are moved through whole QuEChERS procedure. Then the recovery were calculated and it is summarized in Table 4.

The obtained data shows recovery from $71 \%$ to $120 \%$ which is in a very good correlation with requirements of legislation where accepted recovery is between $50 \%$ and $120 \%$ [39].

Finally, LOD values of modified GC/MS method and for the instrument were determined and they are presented in Table 5.

\section{CONCLUSIONS}

A fast and easy to realize GC/MS method for determination of 16 PAHs under the control of International and European legislation was created and validate. Two different methods for sample preparation were used and compared according to their rapidity and suitability for aim compounds determination. The created modified QuEChERS method is realized in a single step. It is easy and fast for realization and it led to obtaining of pure analytical results for aimed compounds fitting with requirements of the International legislation.

\section{ACKNOWLEDGMENTS}

Authors would like to thank to Testing center Global Test Ltd for providing the opportunities to use all specific equipment.

\section{REFERENCES}

1. Moret, S.; Conte, L. S. J. Chromatogr. A 2000, 882, 245. doi: 10.1016/s0021-9673(00)00079-0.

2. Orecchioa, S.; Papuzza, V. J. Hazard Mater. 2009, 164, 876. doi: 10.1016/j.jhazmat.2008.08.083.

3. Ravindra, K.; Sokhi, R.; Van Grieken, R. Atmos. Environ. 2008, 42, 2895. doi: 10.1016/j.atmosenv.2007.12.010.

4. Majumdar, D.; Rajaram, B.; Meshram, S.; Rao C. Crit. Rev. Environ. Sci. Technol. 2012, 42, 1191. doi: 10.1080/ 10643389.2011.556550.

5. Pissinatti, R.; Nunes, C. M.; de Souza, A. G.; Junqueira, R. G.; de Souza, S. V. C. Food Contr. 2015, 51, 140. doi: 10.1016/j.foodcont.2014.11.003.

6. Zhang, Y.; Yang, X.; Bian, Y.; Gu, C.; Wang, D.; Jiang, X. Chin. J. Anal. Chem. 2016, 44, 1514. doi: 10.1016/S1872-2040(16) 60961-1.

7. Orecchio, S. J. Hazard Mater. 2010, 173, 358. doi:10.1016/ j.jhazmat.2009.08.088.

8. Yuan, X.; Jiang, Y.; Yang C.; Xie B.; Yong L.; Hu B.; Liu T. Chin. J. Anal. Chem. 2017, 45, 1641. https://doi.org/10.1016/S18722040(17)61047-8.

9. Culotta, L.; Gianguzza, A.; Orecchio, S. Polyc. Arom. Comp. 2005, 25, 327. doi: 10.1080/10406630500227262.

10. Moret, S.; Purcaro, G.; Conte, L. S. Sci. Tot. Environ. 2007; 386, 1. doi: 10.1016/j.scitotenv.2007.07.008.

11. Lorenzi, D., Entwistle, J. A.; Cave, M.; Dean, J. R. Chemosphere 2011, 83, 970. doi:10.1016/j.chemosphere.2011.02.020.

12. Hunter, S.; Myers, S.; Radmacher, P.; Eno C. Polycycl. Aromat. Comp. 2010, 30, 153, doi: 10.1080/10406638.2010.483629. 
13. Bansal, V.; Kumar, P.; Kwon, E. E.; Kim, K. Crit. Rev. Food Sci. Nutr. 2017, 57, 3297. doi: 10.1080/10408398.2015.1116970.

14. Pino, V.; Ayala, J. H.; Afonso, A. M.; Gonzalez V. J. Chromatogr. A 2002, 949, 291. doi: 10.1016/S0021-9673(01)01589-8.

15. Khorshid, M.; Souaya, E. R.; Hamzawy, A. H.; Mohammed, M. N. Int. J. Environ. Anal. Chem. 2015, 7. doi: 10.1155/2015/352610.

16. Serpe, F. P.; Esposito, M.; Gallo, P.; Serpe, L. Food Chem. 2010, 122, 920. doi: 10.1016/j.foodchem.2010.03.062.

17. Zhang, H.; Xue, M.; Dai, Z. J. Food Compos. Anal. 2010, $23,469$. doi: 10.1016/j.jfca.2009.12.016.

18. Veyrand, B.; Brosseaud, A.; Sarcher, L.; Varlet, V.; Monteau, F.; Marchand, P.; Andre, F.; Le Bizec, B. J. Chromatogr. A 2007, 1149, 333. doi: 10.1016/j.chroma.2007.03.043.

19. ATSDR, Environmental Medicine. Environmental Health Education (2011-07-01). Toxicity of Polycyclic Aromatic Hydrocarbons (PAHs): Health Effects Associated With PAH Exposure. Retrieved 2016-02-01.

20. Brazkova, M.; Krastanov, A. Polycyclic aromatic hydrocarbons: Sources, effects and biodegradation. Book 10.2/Proceedings Biotechnologies and food technologies 2013, 52, 52.

21. Ramesh, A.; Archibong, A.; Hood, D. B.; Guo, Z.; Loganathan, B. G. Global Environmental Distribution and Human Health Effects of Polycyclic Aromatic Hydrocarbons. Global Contamination Trends of Persistent Organic Chemicals. CRC Press: Boca Raton, FL, 2011, pp 97-126.

22. Commission Regulation (EC). No 1881/2006 of 19 December 2006 setting maximum levels for certain contaminants in foodstuffs.

23. Purcaro, G.; Moret, S.; Conte L. S. Talanta 2013, 105, 292. doi: 10.1016/j.talanta.2012.10.041.

24. Wenzl, T.; Simon, R.; Kleiner, J.; Anklam, E. Trends Anal. Chem. 2006, 25, 716. doi:10.1016/j.trac.2006.05.010.
25. Janoszka, B. Food Chem. 2011, 126, 1344. doi:10.1016/j.foodchem.2010.11.097.

26. Silva, S. A. D.; Sampaio, G. R.; da Silva Torres, E. A. F. Food Chem. 2017, 221, 809. doi:10.1016/j.foodchem.2016.11.098.

27. Olatunji, O. S.; Fatoki, O. S.; Opeolu, B. O.; Ximba, B. J. Food Chem. 2014, 156, 296. doi:10.1016/j.foodchem.2014.01.120.

28. Plaza-Bolanos, P.; Frenicha, A. G.; Vidal, J. L. M. J. Chromatogr. A 2010, 1217, 6303. doi:10.1016/j.chroma.2010.07.079.

29. Yurchenko, S.; Molder, U. J. Food Compos. Anal. 2005, $18,857$. doi:10.1016/j.jfca.2004.11.004.

30. Aguinaga, N.; Campillo, N.; Vinas, P.; Hernandez-Cordoba, M. Anal. Chim. Acta 2007, 596, 285. doi:10.1016/j.aca.2007.06.005.

31. Veyrand, B.; Brosseaud, A.; Sarcher, L.; Varlet, V.; Monteau, F.; Marchand, P.; Andre, F.; Le Bizec, B. J. Chromatogr. A 2007, 1149, 333. doi:10.1016/j.chroma.2007.03.043.

32. Sanchez-Brunete, C.; Miguel, E.; Tadeo, J. L. J. Chromatogr. A 2007, 1148, 219. doi:10.1016/j.chroma.2007.03.026.

33. Mohammad, S. A.; Ghanemi, K.; Larki, A. J. Chromatogr. A 2016, 1476, 9. doi:10.1016/j.chroma.2016.11.022.

34. Rawa-Adkonis, M.; Wolska L.; Namieśnik J. Crit. Rev. Anal. Chem. 2003, 33, 199. doi:10.1080/713609164.

35. Viegas, O.; Novo, P.; Pinho, O.; Ferreira I. M. P. L. V. O. Talanta 2012, 88, 677. doi:10.1016/j.talanta.2011.11.060.

36. Givechev, I.; Danalev, D.; Yaneva, S.; Tanev, D. JCTM 2018, 53, 717.

37. Surma, M.; Sadowska-Rociek, A.; Cieslik, E. Eur. Food Res. Technol. 2014, 238, 1029. doi:10.1007/s00217-014-2181-4.

38. Al-Thaiban, H.; Al-Tamimi, N.; Helaleh M. J. Anal. Methods Chem. 2018, 11. doi: 10.1155/2018/9206237.

39. Commission Regulation (EC) No 333/2007 of 28 March 2007 laying down the methods of sampling and analysis for the official control of the levels of lead, cadmium, mercury, inorganic tin, 3-MCPD and benzo[a]pyrene in foodstuffs. 